\title{
Use of plasticizers in the production of PMB, as a tool for creating effective binders
}

\author{
Marina Vysotskaya ${ }^{1,}{ }^{*}$, Dmitry Litovchenko ${ }^{1}$, Artem Shiryaev ${ }^{1}$, and Maxim Lashin ${ }^{1}$ \\ ${ }^{1}$ Belgorod State Technological University VG Shukhov, Kostukova str., 46, Belgorod, 308012, Russia
}

\begin{abstract}
Currently, the use of an appropriate type of binder suitable for specific climate conditions has become an important area for ensuring the operational reliability of asphalt concrete coatings. However, it is worth noting that the required set of PMB properties depends not only on the percentage of the polymer, but also on the type of plasticizer used. The results of comparative tests of polymerbitumen binders prepared using 6 different plasticizing additives are presented. The dependence of changes in the parameters of modified binders, as well as their thermal stability, is studied. Based on the analysis of generalized efficiency criteria, a Comprehensive assessment of the effect of the plasticizer on the properties of the final product - PMB-was performed. The result demonstrates the need to use plasticizing components to achieve the required properties of the modified binder. Recommendations are given to maintain the required level of physical and mechanical parameters of PMB.
\end{abstract}

\section{Introduction}

The most important task the domestic oil industry facing today is the modernization and deepening of heavy oil refining. The criterion for the effectiveness of oil refining is the amount of light petroleum products (gasoline, kerosene, etc.) and lubricating oils. Implemented approaches and modernization of production entail significant changes in the tonnage and properties of the resulting residues, as well as introduce dissonance in the "producer - consumer" system

In general, current situation prevailing in related industries and emerging issues is illustrated in Figure 1.

*Corresponding author: roruri@rambler.ru 


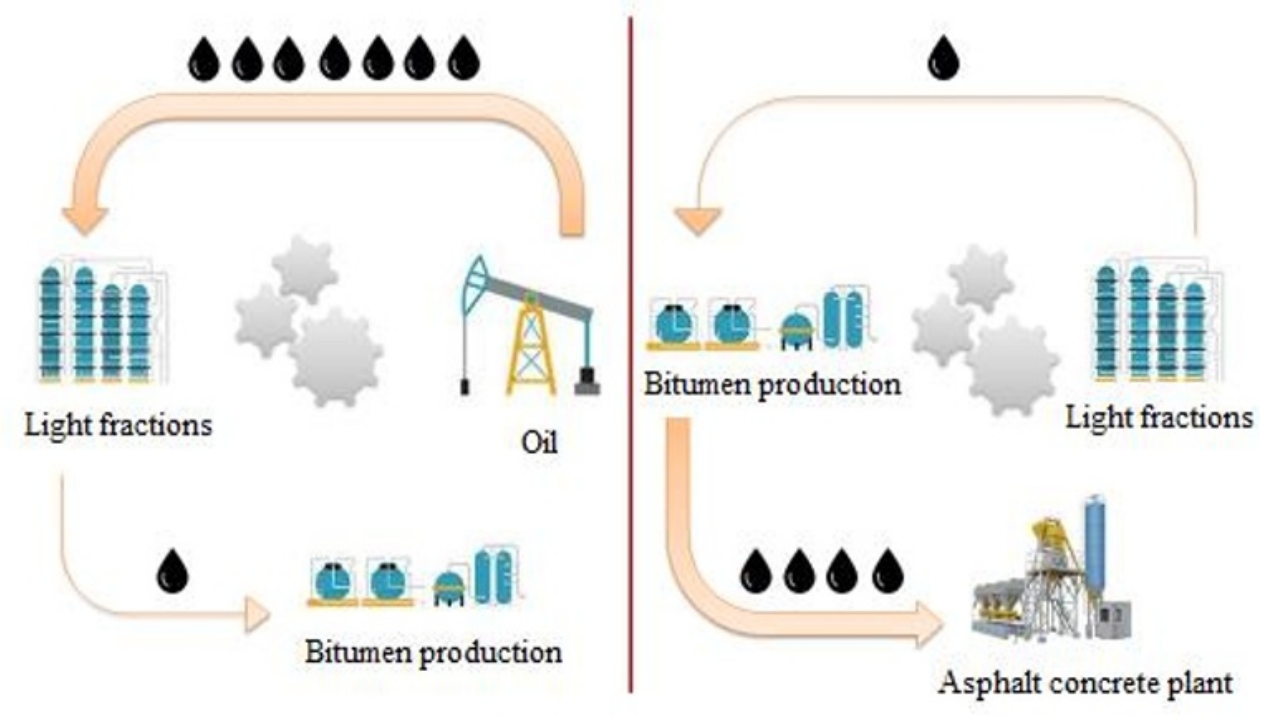

Fig.1. Scheme of the ambiguity of bitumen production

Raw materials after maximum "squeezing" of light fractions are involved in the technology of production of organic binders for construction needs. Moreover, the development of oil refining technologies systematically reduces the volume of residues. The reverse trend is observed in the road construction industry: a significant increase in the consumption of bitumen and their derivatives, as well as an increase in quality parameters for use in the industry.

Tighter requirements in road construction segment for the quality of "commodity" binders: oil bitumen and their derivatives, dictates the need to take into account their rheological parameters at the stage of selection of asphalt mixes and exacerbates the situation. In view of the deepening of oil refining, heavy oil residues are dispersed systems with a depleted dispersion medium, and a significant content of the dispersion phase - asphaltenes. This necessitates adjusting the group composition of the binder $[1,2]$ to restore balance in the content of asphaltene-maltene. This is important in case of polymer bitumen modification, in the preparation of a polymer-bitumen binder (PMB) [3].

One of the methods for controlling the rheological properties of both bitumen and polymer bitumen binders for various operating and purpose conditions is adding the plasticizers [4,5]. The use of this method demonstrates that in systems filled with the maltene part, when combined with the polymer, a plasticizing effect is observed that promotes the development of plastic deformation of the samples rather than brittle fracture, especially at low temperatures. This leads to an increase in the tensile elongations of the modified binder, fracture energy and elasticity.

\section{Objects and methods}

In accordance with the laws of colloid chemistry, the stability of disperse systems, which include bitumen, depends on the degree of affinity of the maltene part (medium) and asphaltenes (phase). In case of instability, systems tend to phase separation. Especially these processes are observed during storage, pumping, compounding and heating. So, for example, in bitumen with a high content of asphaltenes and paraffin-naphthenic hydrocarbons during PMB preparation, product separation can be observed due to the precipitation of the 
asphaltene phase.

This behavior of the binder demonstrates the feasibility of using bitumen with penetration of $130-200$ and $200-300 \mathrm{~mm}^{-1}$ for the preparation of polymer bitumen binders, in which the maltene - asphaltene ratio is optimal, in this case plasticization is not required.

The classification of bitumen binders by PG (Performance Grade) affects the production of bitumen binders, introducing certain adjustments to it. Particular attention should be paid to the brands PG 70/40 and PG 52/46, the receipt of which is not possible without the additional introduction of a plasticizing component. Thus, today the use of plasticizer is an effective tool to achieve the specified low-temperature parameters of the modified binder.

The purpose of the work is to substantiate the need for the use of a plasticizer in the manufacture of PMB marked according to PG.

In the present work a series of 6 different plasticizers, was considered, in table 1. Bitumen grade BND 70/100 from JSC "Gazproneft MNPZ", the properties are presented in table 2, and the polymer SBS L 30-01 A from JSC "Voronezhsintezkauchuk" a linear block copolymer based on styrene and butadiene with a content of bound styrene of $30 \%$ by weight, contains a non-coloring stabilizer. It is a high-strength polymer with a high degree of elasticity and is used for the modification of bitumen intended for paving, plastic modification, for the manufacture of adhesives, tape sealant, and for the manufacture of protective coatings.

Table 1. Plasticizers used forthe preparation of polymer bitumen binders

\begin{tabular}{|l|l|}
\hline № & Name of the plasticizer \\
\hline 1 & Selective activity extract \\
\hline 2 & Mark A extract \\
\hline 3 & Superplasticizer \\
\hline 4 & I-20 oil \\
\hline 5 & Fuel oil \\
\hline 6 & Met fraction \\
\hline
\end{tabular}

Table 2. Physico-mechanical properties of bitumen BND 70/100

\begin{tabular}{|c|c|c|}
\hline Name of indicators & $\begin{array}{l}\text { GOST } 33133 \\
\text { requirements }\end{array}$ & Actual Results \\
\hline $\begin{array}{l}\text { The penetration depth of the needle is } 0.1 \mathrm{~mm} \text {, } \\
\text { at } 25^{\circ} \mathrm{C} \\
\text { at } 0^{\circ} \mathrm{C}\end{array}$ & $\begin{array}{l}71-100 \\
>21\end{array}$ & $\begin{array}{l}77 \\
24\end{array}$ \\
\hline $\begin{array}{l}\text { Elongation, cm, } \\
\text { at } 25^{\circ} \mathrm{C} \\
\text { at } 0^{\circ} \mathrm{C} \\
\end{array}$ & $\begin{array}{l}>62 \\
>3.7\end{array}$ & $\begin{array}{l}100 \\
3.7\end{array}$ \\
\hline $\begin{array}{l}\text { Maximum tensile for force } \mathrm{N} \text {, at temperature, } \\
\text { at } 25^{\circ} \mathrm{C} \\
\text { at } 0^{\circ} \mathrm{C}\end{array}$ & - & $\begin{array}{l}1.2 \\
118\end{array}$ \\
\hline Softening temperature ${ }^{0} \mathrm{C}$ & $>47$ & 49.5 \\
\hline Fragility temperature,${ }^{0} \mathrm{C}$ & $<-18$ & -22 \\
\hline Dynamic viscosity, $\mathrm{Pa} \cdot \mathrm{s}$, at $60^{\circ} \mathrm{C}$, Condition 1 & - & 245.5 \\
\hline $\begin{array}{l}\text { Change in dynamic viscosity after shear, } \mathrm{Pa} \cdot \mathrm{s} \text {, at } 60^{\circ} \mathrm{C} \text {, Condition } \\
2\end{array}$ & - & 12.97 \\
\hline \multicolumn{3}{|l|}{ RTFOT post-aging tests } \\
\hline Change in mass of the sample after aging, $\%$ & $<0.6$ & 0.2 \\
\hline Change in softening temperature, ${ }^{0} \mathrm{C}$, after aging & $<7$ & 6.2 \\
\hline Dynamic viscosity, $\mathrm{Pa} \cdot \mathrm{s}$, at $60^{\circ} \mathrm{C}$, Condition 1 & - & 667.11 \\
\hline $\begin{array}{l}\text { Change in dynamic viscosity after shear, } \mathrm{Pa} \cdot \mathrm{s} \text {, at } 60^{\circ} \mathrm{C} \text {, Condition } \\
\text { L }\end{array}$ & - & 24.72 \\
\hline Fragility temperature after aging, ${ }^{0} \mathrm{C}$ & $<-15$ & -19 \\
\hline
\end{tabular}

The choice of brand of bitumen is justified by its representation in the market of bitumen 
materials. The content of plasticizer and polymer was $(4.5 \pm 0.5) \%$ and $(3.5 \pm 0.5) \%$, respectively. The bitumen used complies with the requirements GOST 33133-2014 of BND 70/100.

Standard methods were used to assess the quality of the obtained binder samples. The homogeneity of the polymer-plasticizer system was assessed visually by fluorescence microscopy.

\section{Results}

The basis for determining the upper $(\mathrm{X})$ and lower $(\mathrm{Y})$ values of the binder mark according to $\mathrm{PG}$ is:

- assessment of binder shear resistance by applying an alternating sinusoidal shear load to a sample prepared by the RTFOT method, followed by determination of the complex shear modulus;

- assessment of the resistance of the binder load at a given negative temperature, by applying a concentrated static load on the beam sample of an organic binder prepared according to the PAV method, followed by determination of the parameters of rigidity and creep.

Table 3. Properties of PMB got with different plasticizers

\begin{tabular}{|c|c|c|c|c|c|c|c|c|c|c|c|}
\hline \multirow{3}{*}{$\begin{array}{l}\text { Plasticizer } \\
\text { name in } \\
\text { making } \\
\text { polymer } \\
\text { bitumen } \\
\text { binder }\end{array}$} & \multicolumn{2}{|c|}{$\begin{array}{l}\text { Dynamic } \\
\text { viscosity, } \\
\mathrm{Pa} \cdot \mathrm{s}\end{array}$} & \multirow{3}{*}{$\begin{array}{l}\text { Integ } \\
\text { rated } \\
\text { shear } \\
\text { modu } \\
\text { lus } \\
\text { befor } \\
\text { e } \\
\text { aging } \\
,{ }^{\circ} \mathrm{C}\end{array}$} & \multirow{3}{*}{$\begin{array}{l}\text { Mass } \\
\text { chan } \\
\text { ge, } \\
\%\end{array}$} & \multirow{3}{*}{$\begin{array}{l}\text { Comprehe } \\
\text { nsive } \\
\text { shear } \\
\text { modulus } \\
\text { after aging } \\
\text { RTFOT, } \\
{ }^{\circ} \mathrm{C}\end{array}$} & \multicolumn{6}{|c|}{ Rigidity on a bending beam rheometer (BBR) } \\
\hline & & & & & & \multicolumn{2}{|l|}{$-12^{\circ} \mathrm{C}$} & \multicolumn{2}{|l|}{$-18^{\circ} \mathrm{C}$} & \multicolumn{2}{|l|}{$-24^{\circ} \mathrm{C}$} \\
\hline & $\begin{array}{l}135^{\circ} \\
\mathrm{C}\end{array}$ & $165^{\circ} \mathrm{C}$ & & & & $\begin{array}{l}\text { rigidi } \\
\text { ty } \\
\mathrm{MPa}\end{array}$ & $\begin{array}{l}\text { cree } \\
\mathrm{p}\end{array}$ & $\begin{array}{l}\text { rigidit } \\
\mathrm{y} \\
\mathrm{MPa}\end{array}$ & $\begin{array}{l}\text { cree } \\
\mathrm{p}\end{array}$ & $\begin{array}{l}\text { rigidit } \\
\mathrm{y} \\
\mathrm{MPa}\end{array}$ & creep \\
\hline Plasticizer (1) & 1.817 & 0.474 & 80.5 & 0.26 & 78.6 & - & - & 124.63 & 0.323 & 248.42 & 0.299 \\
\hline $\begin{array}{ll}\text { Mark } & A \\
\text { extract (2) } & \\
\end{array}$ & 1.866 & 0.423 & 81.2 & 0.30 & 80.4 & - & - & 125.49 & 0.327 & 242.55 & 0.298 \\
\hline $\begin{array}{l}\text { Superplastici } \\
\text { zer (3) }\end{array}$ & 1.508 & 0.362 & 78.1 & 0.83 & 70.1 & - & - & 118.62 & 0.305 & 263.74 & 0.257 \\
\hline $\begin{array}{l}\text { Industrial oil } \\
\text { (4) }\end{array}$ & 1.653 & 0.391 & 77.1 & 0.81 & 73.1 & - & - & 116.85 & 0.302 & 246.64 & 0.267 \\
\hline Fuel Oil (5) & 1.954 & 0.545 & 83.6 & 0.36 & 80.9 & - & - & 136.54 & 0.315 & 258.87 & 0.285 \\
\hline $\begin{array}{l}\text { Met Fraction } \\
\text { (6) }\end{array}$ & 2.152 & 0.653 & 84.8 & 0.21 & 81.8 & - & - & 131.14 & 0.314 & 261.49 & 0.285 \\
\hline $\begin{array}{l}\text { BND } 70 / 100 \\
\text { (7) }\end{array}$ & 0.389 & 0.106 & 65.1 & 0.38 & 62.5 & - & - & 166.45 & 0.304 & 325.83 & 0.265 \\
\hline $\begin{array}{l}\text { No plasticizer } \\
\text { (8) }\end{array}$ & 2.798 & 0.878 & 86.8 & 0.24 & 71.4 & 148.18 & 0.339 & 133.50 & 0.289 & - & - \\
\hline
\end{tabular}

During the experiment, it was necessary, slightly varying the content of plasticizer, to reach the mark of modified binder PG76 / 28. The range of variation in the content of plasticizer was adopted $(4.5 \pm 0.5) \%$. Assessment of prepared polymer bitumen binder was carried out in accordance with PNST 85. The results are presented in table 3.

Based on the studies presented in table 3, the binders were classified by PG. The classification of binders got using different plasticizers, can be seen in table 4 .

Table 4. PG binder classification

\begin{tabular}{|l|l|l|l|l|l|l|l|l|}
\hline \multicolumn{1}{|l|}{ Plasticizer name in making polymer bitumen binder } \\
\hline \multirow{3}{*}{$\begin{array}{l}\text { Binder } \\
\text { mark }\end{array}$} & $\begin{array}{l}\text { Plasticizer } \\
(1)\end{array}$ & $\begin{array}{l}\text { Mark A } \\
\text { extract (2) }\end{array}$ & $\begin{array}{l}\text { Superplasticizer } \\
(3)\end{array}$ & $\begin{array}{l}\text { Industrial } \\
\text { oil (4) }\end{array}$ & $\begin{array}{l}\text { Fuel } \\
\text { Oil } \\
(5)\end{array}$ & $\begin{array}{l}\text { Met } \\
\text { Fraction } \\
(6)\end{array}$ & $\begin{array}{l}\text { BND } \\
70 / 100 ~(7)\end{array}$ & $\begin{array}{l}\text { No } \\
\text { plasticizer } \\
(8)\end{array}$ \\
\cline { 2 - 9 } & $76 / 28$ & $76 / 28$ & $70 / 28$ & $70 / 28$ & $76 / 28$ & $76 / 28$ & $58 / 28$ & $70 / 22$ \\
\hline
\end{tabular}

Table 3 and 4 shows that the initial bitumen is classified as PG58/28, the second digit in the classification is the stiffness index on a beam bending rheometer (BBR), characterizing 
the possibility of resistance to binder cracking at a low temperature. The introduction of a polymer into its composition facilitates the transition of the binder to the PG70 / 22 mark. While an increase in the upper limit of the binder and a subsidence of low-temperature characteristics are observed, which is explained by the lack of maltens in bitumen for plasticizing the polymer, and is not permissible for most regions of the Russian Federation. Moreover, it was not possible to dissolve the entire polymer in bitumen without a plasticizer, without changing the time and temperature of mixing the composition. The exclusion from the composition of the polymer-bitumen binder plasticizing component significantly increases the dynamic viscosity of the system at temperatures of $135^{\circ} \mathrm{C}$ and $165^{\circ} \mathrm{C}$, the complex shear modulus before and after aging, which gives the polymer bitumen binder a very high viscosity when pumping the binder through a piping system, mixing with the mineral part of asphalt concrete mixtures and complicates the execution of technological operations on road-building facilities, negatively affects the workability and compactability of polymer-asphalt concrete on its basis [6,7].

The enrichment of bitumen with hydrocarbons through the introduction of a plasticizer, on the contrary, can significantly expand the low-temperature range of the binder and achieve the required shear modulus in a sufficiently high temperature range.

However, not every plasticizing component allows you to get an astringent, characterized by a combination of desired (projected) properties. Upon a detailed examination of the data in Table 3, it becomes apparent that the polymer bitumen binders samples using plasticizers No. 5 and 6 are sufficiently rigid and are located on the border of the mark.

For binders, plasticized with superplasticizer and industrial oil, compositions 3 and 4, the maximum weight loss after heating is characteristic. But the plasticizer should not be volatile $[8,9]$. The presence of a significant amount of volatile components in the binder determines the high rate of their evaporation during heating, which is an indicator of the binder's tendency to aging and contributes to a significant change in the complex shear modulus after aging according to the RTFOT method. As can be seen, in the indicated samples of binders after aging, the change in the indicator was $8^{\circ} \mathrm{C}$ for polymer bitumen binder with a superplasticizer, and $4^{\circ} \mathrm{C}$ for a sample with industrial oil. Whereas the introduction of other plasticizers changed the considered parameter from 0.8 to $3^{\circ} \mathrm{C}$.

The most stable were compositions 1 and 2 , which during the experiment remained within the predefined mark.

It is obvious that the resulting difference in the properties of the product is associated with different dissolving power of the plasticizers used for the production of PMB. Let's consider the "polymer - plasticizer" system for the most characteristic plasticizers under a microscope, Figure 2-4. The distribution, extent, and homogeneity of various phases in sistems largely depend on various factors, including plasticizer [10-16].

The recorded difference in the systems is obvious. It can be assumed that the degree of such a change depends on the thermodynamic affinity of the plasticizer to the polymer. If the affinity is great (plasticizer is a good solvent for the polymer), then its molecules penetrate into any polymer structures, gradually destroying them.

With intrastructural plasticization, the plasticizer truly dissolves in the polymer in any quantities and affects the conformation and flexibility of macromolecules. With an increase in the volume fraction of the plasticizer, the system continuously decreases to the glass transition temperature of the plasticizer itself. The same thing happens with the viscosity of the system. The better the plasticizer as a solvent, the lower its viscosity, the lower the viscosity of the system. Therefore, the substance, which is a better solvent for this polymer, is also its better plasticizer. 


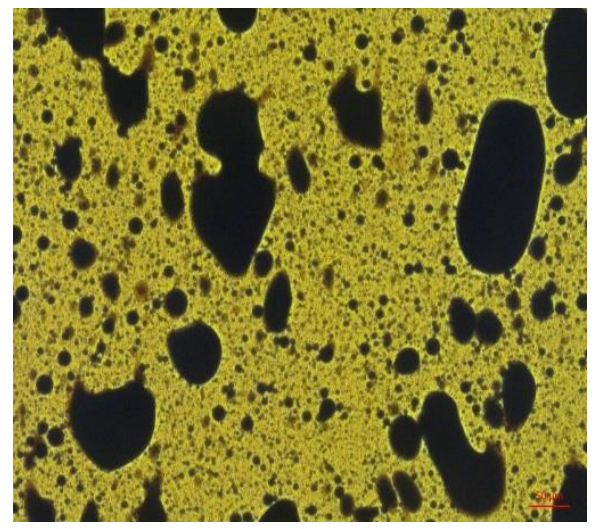

Fig.2. Micrograph of the polymer-plasticizer system using a plasticizer met. fraction (6)

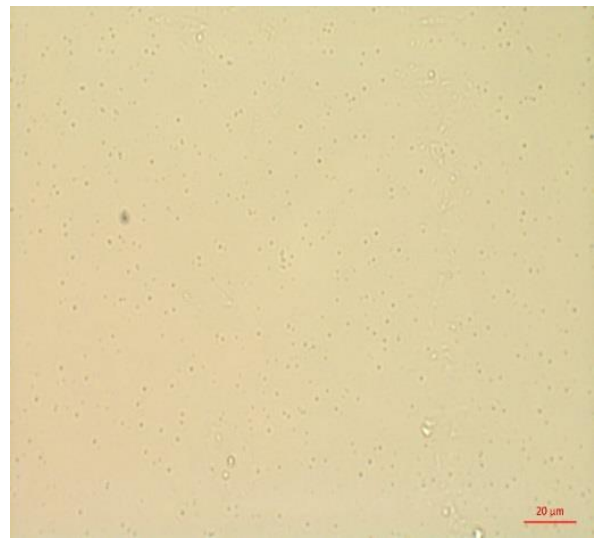

Fig.3. Micrograph of the polymer-plasticizer system using a plasticizer Selective activity extract (1)

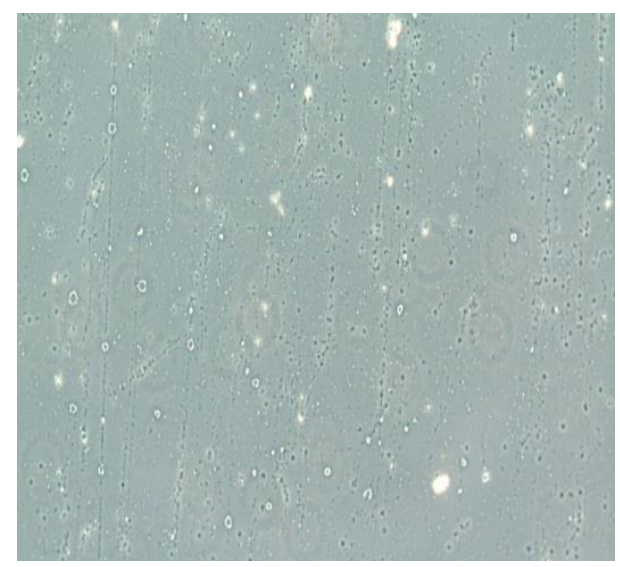

Fig.4. Micrograph of the polymer-plasticizer system using a plasticizer superplasticizer (3)

The put forward assumptions are in good agreement with the results of experimental studies of laboratory samples.

To substantiate the need for the use of plasticizers in the production of PMB, the main parameters of the quality of the binder, regulated PNST 79, were calculated. In accordance with the methodology used, it is necessary to evaluate the effectiveness of each composition made using various plasticizers, table. 3. The assessment is based on the calculation of 
particular performance criteria, calculated by the formula:

$$
K_{\text {ef }}^{i}=\frac{3_{\text {act. }}^{i}}{3_{\text {req. }}^{i}}
$$

where $K_{e f .}^{i}$ - particular criterion for the effectiveness of the i-th indicator;

$3_{\text {act. }}^{i}$ - actual value of the $\mathrm{i}-$ th indicator;

$3_{\text {req. }}^{i}$ - required value of the $i$-th indicator.

The calculation results are presented in table 5 .

Table 5. Particular performance criteria for PMB

\begin{tabular}{|c|c|c|c|c|c|}
\hline \multirow{2}{*}{\multicolumn{2}{|c|}{ Binder }} & \multicolumn{4}{|c|}{ Performance criteria } \\
\hline & & \multirow{2}{*}{$\begin{array}{l}\text { integrated } \\
\text { shear modulus } \\
\text { before aging }\end{array}$} & \multirow{2}{*}{$\begin{array}{l}\mathrm{BBR} \\
\text { rigidity }\end{array}$} & \multirow{2}{*}{$\begin{array}{l}\text { integrated shear } \\
\text { modulus after aging } \\
\text { at RTFOT }\end{array}$} & \multirow[b]{2}{*}{ plasticity } \\
\hline binder composition & $\begin{array}{l}\text { composition } \\
\text { number }\end{array}$ & & & & \\
\hline Bitumen + Plasticizer 1 & 1 & 1.06 & 1.21 & 1.03 & 0.98 \\
\hline Bitumen + mark A extract & 2 & 1.07 & 1.21 & 1.06 & 0.99 \\
\hline Bitumen + Superplasticizer & 3 & 1.03 & 1.02 & 0.92 & 0.93 \\
\hline Bitumen + Industrial oil & 4 & 1.01 & 1.01 & 0.96 & 0.96 \\
\hline Bitumen + Fuel Oil & 5 & 1.10 & 1.11 & 1.06 & 0.98 \\
\hline Bitumen + Met fraction & 6 & 1.12 & 1.10 & 1.08 & 0.97 \\
\hline BND 70/100 & 7 & 0.86 & 1.02 & 0.82 & 0.97 \\
\hline Bitumen without plasticizer & 8 & 1.01 & 0.95 & 0.94 & 0.95 \\
\hline
\end{tabular}

Based on the obtained base of particular performance criteria for PMB made using plasticizers (compositions 1-6) and without (composition 8), as well as the initial bitumen (composition 7), a generalized performance criterion was calculated for each composition.

$$
K_{e f}^{\mathrm{ob}}=\sqrt[6]{N_{n=1}^{i} \cdot K_{e f}^{i}},
$$

The results of the calculation of generalized performance criteria for PMB formulations made with and without plasticizers are presented in the form of a diagram in Figure 5.

A comprehensive assessment of the effect of a plasticizer on the properties of the final product - PBB, based on an analysis of generalized performance criteria, demonstrates the need to use plasticizing components to achieve the required properties of a modified binder.

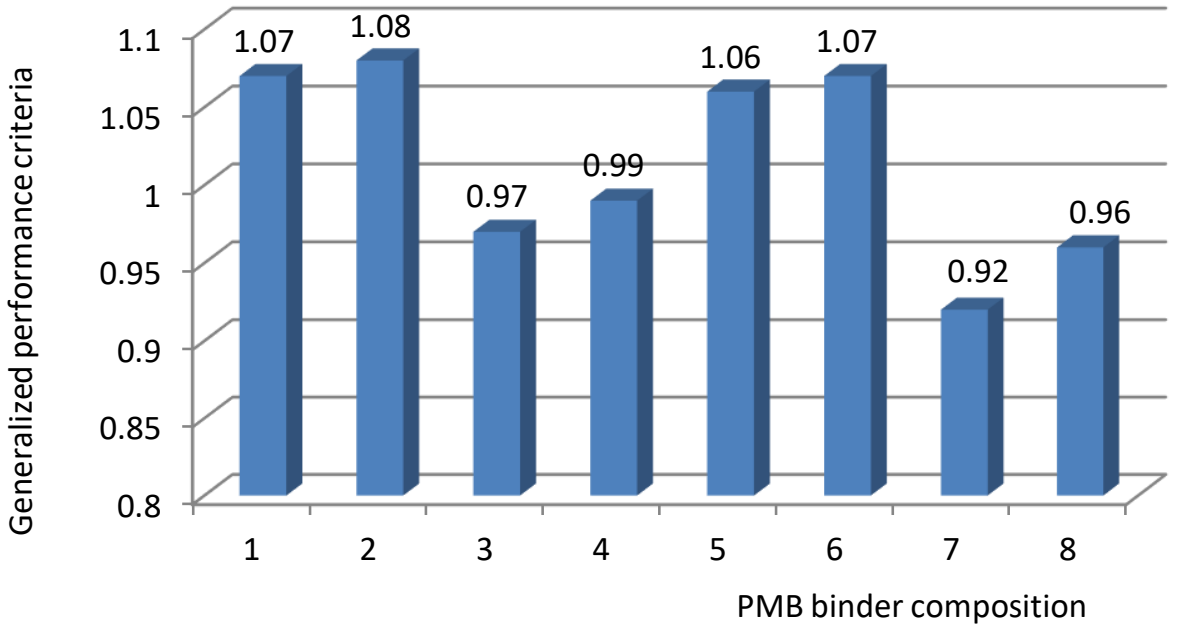

Fig. 5. Generalized performance criteria for PMB compositions 


\section{Conclusion}

Thus, the presence of plasticizing components in a binder is not only an important, but also a necessary condition for obtaining high-quality PMB [17,18]. However, it is necessary to develop parameters of the effectiveness of plasticizers and methods for their assessment, allowing to predict the work and durability of the composition. Also, varying only the content of plasticizer, it becomes possible to adjust the lower limit of the mark by PG for use in regions with low winter temperatures. Moreover, an increase in high-temperature parameters, if necessary, becomes possible due to an increase in the polymer content.

Moreover, the introduction of a plasticizer allows us to speed up the process of preparing polymer bitumen binders, to provide a gentle temperature regime for its preparation (not higher than $160^{\circ} \mathrm{C}$ ), and also significantly increase the efficiency of the introduced polymer.

The work was carried out as part of Presidential grant for scientific schools NSh-NSh-2584.2020.8.

\section{References}

1. Lu Sun, Y. Wang, Y. Zhang, Construction and Building Materials, 70, 26-35 (2014) DOI: 10.1016/j.conbuildmat.2014.07.064

2. K. Kumar, A. Singh, et al., Journal of Industrial and Engineering Chemistry, 44, 112-117 (2016) DOI: 10.1016/j.jiec.2016.08.017

3. X. Yu, N.A. Burnham, S. Granados-Focilc, M. Tao, Fuel, 254, 115509 (2019) DOI: 10.1016/j.fuel.2019.05.092

4. D. Lesueur, Advances in Colloid and Interface Science, 145(1-2), $42-82$ (2009) DOI: 10.1016/j.cis.2008.08.011

5. R. Tauste, F. Moreno-Navarro, M. Sol-Sánchez, M.C. Rubio-Gámez, Construction and Building Materials, 192, 593-609 (2018) DOI: 10.1016/j.conbuildmat.2018.10.169

6. M. Mirsepahi, J. Tanzadeh, S. Alireza Ghanoon, Construction and Building Materials, 233, 117183 p. (2020) DOI: 10.1016/j.conbuildmat.2019.117183

7. J.C. Munera, E.A. Ossa, Materials \& Design (1980-2015), 62, 91-97 (2014) DOI: 10.1016/j.matdes.2014.05.009

8. R. Tauste, F. Moreno-Navarro, M. Sol-Sánchez, M. C. Rubio-Gámez Construction and Building Materials, 192, 593-609 (2018) DOI: 10.1016/j.conbuildmat.2018.10.169

9. J. Zhu, B. Birgisson, N. Kringos European Polymer Journal, 54, 18-38 (2014) DOI: 10.1016/j.eurpolymj.2014.02.005

10. P.S. Belyaev, S.V. Mishchenko, V.P. Belyaev, V.A. Frolov AIP Conference Proceedings, 1876, 020096 p. (2017) DOI: 10.1063/1.499891

11. L. Zani, F. Giustozzi, J. Harvey Construction and Building Materials, 145, 326-335 (2017) DOI: 10.1016 / j.conbuildmat.2017.04.014

12. J. Zhu, R. Balieu, X. Lu, N. Kringos Journal of Materials Science, 52(11), 6525-6541 (2017) DOI: 10.1007/s10853-017-0887-y

13. G. Holleran, I. Holleran, D.J. Wilson Conference Series: Materials Science and Engineering. Building up Efficient and Sustainable Transport Infrastructure, 236(1), 012009 (2017) DOI:10.1088/1757-899X/236/1/012009

14. N. Zainab Habib, I. Kamaruddin, I.M. Tan, Road Materials and Pavement Design, 18, 249-258 (2017) 
15. C. Oliviero Rossi, S. Ashimova, et al., Applied Sciences (Switzerland), 7(8), 779 (2017) DOI: 10.3390 / app7080779

16. N. Zainab Habib, I. Kamaruddin, I.M. Tan, M. Komiyama International Conference on Advances in Sustainable Construction Materials and Civil Engineering Systems, 120, 07002 (2017)

17. M. Naskara, T.K.Chakia, K.S.Reddy Thermochimica Acta, 509(1-2), 127-134 (2010) DOI: 0.1016/j.tca.2010.06.013

18. M.A. Vysotskaya, D.A. Kuznezov, D.P. Litovchenko, D. V. Barkovsky, A. O. Shiryaev Vestnik BGTU im. V.G. Shukhov, 5, 16-23 (2019) DOI: 10.34031/article_5cd6df466bb9e0.32764094 